\title{
The ENETS and AJCC/UICC TNM classifications of the neuroendocrine tumors of the gastrointestinal tract and the pancreas: a statement
}

\author{
Günter Klöppel • Guido Rindi • Aurel Perren • \\ Paul Komminoth • David S. Klimstra
}

Received: 13 April 2010 / Accepted: 14 April 2010 /Published online: 27 April 2010

(C) Springer-Verlag 2010

In 2006 a working group of the European Neuroendocrine Tumor Society (ENETS) developed and published a proposal for a TNM staging classification of the neuroendocrine tumors (NET) of the foregut (stomach, duodenum, and pancreas), accompanied by a grading system [1]. This was followed in 2007 by the publication of a TNM staging

G. Klöppel

Consultation Center for Pancreatic and Endocrine Tumors, Department of Pathology, Technical University of Munich, Munich, Germany

\section{G. Rindi}

Institute of Pathology, U.C.S.C. Policlinico A. Gemelli, Rome, Italy

\section{A. Perren}

Institute of Pathology, University of Bern,

Bern, Switzerland

\section{P. Komminoth}

Institute of Pathology, Stadtspital Triemli,

Zürich, Switzerland

\section{S. Klimstra}

Surgical Pathology Service,

Memorial Sloan-Kettering Cancer Center,

New York, NY, USA

\section{G. Klöppel ( $\varangle)$}

Consultation Center for Pancreatic and Endocrine Tumors, Department of Pathology, Technische Universität München, Ismaningerstr. 22,

81675 Munich, Germany

e-mail: guenter.kloeppel@alumni.uni-kiel.de classification of the midgut and hindgut NETs (ileum, appendix, colon/rectum) from the same group [2]. These were the first TNM classifications to be developed for the NETs that took into account the distinctive growth patterns of these tumors and that differentiated these tumors from the other gastroenteropancreatic (GEP) carcinomas. These classification systems additionally supplemented the WHO classification of the GEP-NETs [3], some aspects of which had already been recognized as prognostically relevant [4]. In the years that followed the publication of these proposed TNM classifications, the classifications that concerned the foregut GEP-NETs and particularly the pancreatic NETs were validated by several studies, and their biological relevance and power to discriminate among prognostic groups was largely confirmed [5-9].

In 2009 the seventh edition of the AJCC/UICC TNM classification of the most important malignant tumors appeared [10]. It also includes new TNM staging classifications of the gastrointestinal carcinoids and of pancreatic neuroendocrine tumors, which had not previously been included in the AJCC/UICC staging classifications. However, the seventh edition of the AJCC/UICC TNM classification does not apply to high grade (large cell and small cell) neuroendocrine carcinomas and does not exactly follow the ENETS classifications for some of the anatomic sites. No data are presented to justify the use of different staging parameters. The result is that there now exist two parallel systems, each of which uses identical TNM terminology but may refer to different types and extents of disease for certain NETs. This discrepancy will lead to much confusion among clinicians and will likely limit the ability to compare research 
Table 1 Comparison of the criteria for the T category in the ENETS and UICC TNM classifications of pancreatic neuroendocrine tumors

\begin{tabular}{lll}
\hline & ENETS TNM & AJCC/UICC TNM \\
\hline T1 & $\begin{array}{c}\text { Confined to pancreas, } \\
<2 \mathrm{~cm}\end{array}$ & Confined to pancreas, $<2 \mathrm{~cm}$ \\
T2 & Confined to pancreas, & Confined to pancreas, $>2 \mathrm{~cm}$ \\
& $2-4 \mathrm{~cm}$ & \\
T3 & Confined to pancreas, & Peripancreatic spread, but \\
& $>4 \mathrm{~cm}$, or invasion of & without major vascular \\
& duodenum or bile duct & A. mesent. sup.) \\
& Invasion of adjacent & Major vascular invasion \\
T4 & organs or major vessels & \\
\hline
\end{tabular}

studies that utilize TNM staging as a prognostic factor or to stratify treatment.

Specifically, the AJCC/UICC and ENETS classifications differ in the definitions of the $\mathrm{T}$ stages for the tumors of the pancreas and appendix (Tables 1 and 2). In the case of the pancreatic NETs, the difference is that the AJCC/UICC applies the same TNM classification used for the exocrine pancreatic tumors to the pancreatic NETs (Table 1). To distinguish pT2 from pT3, this system requires recognition of peripancreatic soft tissue invasion, independent of tumor size, a feature very difficult to assess. According to a study presented at the last meeting of the ENETS Advisory Council in November 2009, NETs of the pancreas differ prognostically with regard to their ENETS $\mathrm{T}$ category, but not with regard to the corresponding AJCC/UICC T category. Publication of the aforementioned study is planned for 2010. In the case of the appendiceal NETs, the defined tumor size classes used in the AJCC/UICC system differ considerably from those in the ENETS classification (Table 1). Moreover, invasion of the mesoappendix is omitted. Instead, invasion of the cecum and ileum, a finding very rarely observed in appendix NETs, is introduced as a criterion for T2/T3.

Table 2 Comparison of the criteria for the T category in the ENETS and 7th edition- AJCC/UICC TNM classifications of appendiceal neuroendocrine tumors

\begin{tabular}{lll}
\hline & ENETS TNM & AJCC/UICC TNM. \\
\hline T1 & $\leq 1 \mathrm{~cm}$; invasion of muscularis & T1a,$\leq 1 \mathrm{~cm}$ \\
& propria & T1b, $>1-2 \mathrm{~cm}$ \\
T2 & $\leq 2 \mathrm{~cm}$ and $<3 \mathrm{~mm}$ invasion of & $>2-4 \mathrm{~cm}$ or invasion of \\
& subserosa $/$ mesoappendix & cecum \\
T3 & $>2 \mathrm{~cm}$ or $>3 \mathrm{~mm}$ invasion of & $>4 \mathrm{~cm}$ or invasion of \\
& subserosa $/$ mesoappendix & ileum \\
T4 & invasion of peritoneum/other & invasion of peritoneum/ \\
& organs & other organs \\
& & \\
\hline
\end{tabular}

The TNM staging for the other sites in the gastrointestinal tract is similar in the two systems, although subtle differences in stage groupings persist.

For the present, the intention of this brief statement is to raise awareness about the existence of the differing criteria for staging GEP-NETs. Since the ENETS system was proposed 3-4 years earlier, it is already in widespread use in Europe. In the United States, many practitioners will be mandated to use the AJCC/UICC system. The confusion that will likely arise from these parallel systems is regrettable. When a TNM classification is being applied in practice, it is consequently important to make clear which classification is being used. Another point is that, given the differences in these two systems, it is critical to document in the pathology reports the underlying features that contribute to the T-stage classification (tumor size, extent of invasion, etc.), to allow translation between ENETS and AJCC/UICC classifications [11].

Collection of additional clinical follow-up data may help to refine the staging parameters, and it is hoped that use of such data will be the basis for future modifications of the TNM staging systems, rather than employing arbitrary criteria to modify existing classifications. The data accumulated since the proposal of the ENETS system do provide validation for the staging parameters in that system. Only time will tell whether the variations introduced in the AJCC/UICC system will confer sufficiently enhanced stratification of survival to justify the confusion this alternative classification will cause.

\section{References}

1. Rindi G, Klöppel G, Ahlman H, Caplin M, Couvelard A, de Herder WW, Eriksson B, Falchetti A, Falconi M, Komminoth P, Körner M, Lopes JM, McNicol AM, Nilsson O, Perren A, Scarpa A, Scoazec JY, Wiedenmann B, all other Frascati Consensus Conference participants (2006) TNM staging of foregut (neuro) endocrine tumors: a consensus proposal including a grading system. Virchows Arch 449:395-401

2. Rindi G, Klöppel G, Couvelard A, Komminoth P, Körner M, Lopes JM, McNicol AM, Nilsson O, Perren A, Scarpa A, Scoazec JY, Wiedenmann B (2007) TNM staging of midgut and hindgut (neuro)endocrine tumors: a consensus proposal including a grading system. Virchows Arch 451:757-762

3. Solcia E, Klöppel G, Sobin LH, (In collaboration with 9 pathologists from 4 countries) (2000) Histological typing of endocrine tumours. Second Edition. WHO international histological classification of tumours. Springer, Berlin

4. Schmitt AM, Anlauf M, Rousson V, Schmid S, Kofler A, Riniker F, Bauersfeld J, Barghorn A, Probst-Hensch NM, Moch H, Heitz PU, Kloeppel G, Komminoth P, Perren A (2007) WHO 2004 criteria and CK19 are reliable prognostic markers in pancreatic endocrine tumors. Am J Surg Pathol 31:1677-1682

5. Ekeblad S, Skogseid B, Dunder K, Oberg K, Eriksson B (2008) Prognostic factors and survival in 324 patients with pancreatic endocrine tumor treated at a single institution. Clin Cancer Res 14:7798-7803 
6. Fischer L, Kleeff J, Esposito I, Hinz U, Zimmermann A, Friess H, Büchler MW (2008) Clinical outcome and long-term survival in 118 consecutive patients with neuroendocrine tumours of the pancreas. Br J Surg 95:627-635

7. Pape UF, Jann H, Muller-Nordhorn J, Bockelbrink A, Berndt U, Willich SN, Koch M, Rocken C, Rindi G, Wiedenmann B (2008) Prognostic relevance of a novel TNM classification system for upper gastroenteropancreatic neuroendocrine tumors. Cancer 113:256-265

8. La Rosa S, Klersy C, Uccella S, Dainese L, Albarello L, Sonzogni A, Doglioni C, Capella C, Solcia E (2009) Improved histologic and clinicopathologic criteria for prognostic evaluation of pancreatic endocrine tumors. Hum Pathol 40:30-40

9. Scarpa A, Mantovani W, Capelli P, Beghelli S, Boninsegna L, Bettini R, Panzuto F, Pederzoli P, Delle Fave G, Falconi M
(2010) Pancreatic endocrine tumors: improved TNM staging and histopathological grading permit a clinically efficient prognostic stratification of patients. Mod Pathol doi:10.1038/ modpathol.2010.58

10. Sobin LH, Gospodarowicz MK, Wittekind C (2009) UICC: TNM classification of malignant tumours, 7th edn. Wiley-Blackwell, Oxford

11. Klimstra DS, Modlin IM, Adsay NV, Chetty R, Deshpande V, Gönen M, Jensen RT, Kidd M, Kulke MH, Lloyd RV, Moran C, Moss SF, Oberg K, O'Toole D, Rindi G, Robert ME, Suster $\mathrm{S}$, Tang LH, Tzen CY, Washington MK, Wiedenmann B, Yao J (2010) Pathology reporting of neuroendocrine tumors: application of the Delphic consensus process to the development of a minimum pathology data set. Am J Surg Pathol 34:300-313 